\title{
ARTICLE OPEN \\ Eradication of Pseudomonas aeruginosa biofilms and persister cells using an electrochemical scaffold and enhanced antibiotic susceptibility
}

\author{
Sujala T Sultana', Douglas R Call ${ }^{2}$ and Haluk Beyenal ${ }^{1}$
}

Biofilms in chronic wounds are known to contain a persister subpopulation that exhibits enhanced multidrug tolerance and can quickly rebound after therapeutic treatment. The presence of these "persister cells" is partly responsible for the failure of antibiotic therapies and incomplete elimination of biofilms. Electrochemical methods combined with antibiotics have been suggested as an effective alternative for biofilm and persister cell elimination, yet the mechanism of action for improved antibiotic efficacy remains unclear. In this work, an electrochemical scaffold (e-scaffold) that electrochemically generates a constant concentration of $\mathrm{H}_{2} \mathrm{O}_{2}$ was investigated as a means of enhancing tobramycin susceptibility in pre-grown Pseudomonas aeruginosa PAO1 biofilms and attacking persister cells. Results showed that the e-scaffold enhanced tobramycin susceptibility in $P$. aeruginosa PAO1 biofilms, which reached a maximum susceptibility at $40 \mu \mathrm{g} / \mathrm{ml}$ tobramycin, with complete elimination (7.8-log reduction vs control biofilm cells, $P \leq 0.001$ ). Moreover, the e-scaffold eradicated persister cells in biofilms, leaving no viable cells (5-log reduction vs control persister cells, $P \leq 0.001$ ). It was observed that the e-scaffold induced the intracellular formation of hydroxyl free radicals and improved membrane permeability in e-scaffold treated biofilm cells, which possibly enhanced antibiotic susceptibility and eradicated persister cells. These results demonstrate a promising advantage of the e-scaffold in the treatment of persistent biofilm infections.

npj Biofilms and Microbiomes (2016)2:2; doi:10.1038/s41522-016-0003-0

\section{INTRODUCTION}

Chronic and recalcitrant biofilm infections on wounds are often caused by the presence of a bacterial subpopulation of "persister cells" that are particularly tolerant to bacteriostatic antibiotics. ${ }^{1}$ Biofilms protect bacterial communities in part because the extracellular polymeric substances (EPS) that form the biofilm matrix serve as a diffusion barrier. ${ }^{2}$ This barrier limits antibiotic penetration into biofilms ${ }^{3}$ and immobilizes antibiotics. ${ }^{4}$ In addition, the diffusive barrier results in nutrient gradients, causing decreased growth and metabolic inactivity in parts of the biofilm community, which allows persister cells to arise. ${ }^{1}$ In particular, increased persister cell formation is observed in Gram-negative bacterial biofilms because the bacterial cell membranes are composed of lipopolysaccharides that further limit antibiotic penetration into the cells ${ }^{5}$.

In lieu of classical antibiotics, a number of alternative antimicrobial treatments are being explored either individually (e.g., silver, ${ }^{6}$ mannitol $^{7}$ ) or in combination with conventional antibiotics. $^{8-10}$ Unfortunately, high concentrations of these antimicrobials/antibiotics have toxic side effects ${ }^{11,12}$ while at low concentrations they often decompose before completely eliminating biofilm communities. ${ }^{13}$ Moreover, any persister cells can regrow and form biofilms with potentially enhanced tolerance to antibiotics. ${ }^{14}$ Interestingly, the application of an antibiotic in combination with a direct current (DC) (ranging from $\mu \mathrm{A}$ to $\mathrm{mA} / \mathrm{cm}^{2}$ ) can be effective against several Gram-negative bacteria, $^{15,16}$ including against putative persister cells. ${ }^{16}$ The mechanism underlying this effect was unclear until a recent study demonstrated the presence of electrochemically generated $\mathrm{H}_{2} \mathrm{O}_{2}{ }^{17}$ In that study, an electrochemical scaffold (e-scaffold) made of conductive carbon fabric generated $\sim 25 \mu \mathrm{M} \mathrm{H} \mathrm{H}_{2} \mathrm{O}_{2}$ near the surface of the e-scaffold and this was sufficient to reduce an A. baumannii biofilm ( 3-log) that was established on a dermal explant. The constant but relatively low production of $\mathrm{H}_{2} \mathrm{O}_{2}$ did not appear to be cytotoxic to the mammalian tissue. ${ }^{17}$

A similar study demonstrated that electrochemically generated $\mathrm{H}_{2} \mathrm{O}_{2}$ is sufficient to prevent or delay Pseudomonas aeruginosa PAO1 biofilm growth in vitro ${ }^{18}$ despite the production of two important catalase enzymes (katA and katB) that can protect $P$. aeruginosa from $\mathrm{H}_{2} \mathrm{O}_{2} .{ }^{19}$ Nevertheless, complete elimination of mature $P$. aeruginosa PAO1 biofilms by e-scaffold treatment can be difficult. Adjunct antibiotic treatment can be helpful, ${ }^{16}$ but the mechanism underlying this combined effect is not understood. ${ }^{15}$ For instance, Nodzo et al. reported an enhanced efficacy of vancomycin when it was combined with a cathodic potential of $-1.8 \mathrm{~V}_{\mathrm{Ag} / \mathrm{AgCl}}$ against biofilms formed on $\mathrm{Ti}$ implants in a rodent model, but did not report any mechanism. ${ }^{20}$ Niepa et al. reported that a stainless steel (SS304) electrode released metal cations that enhanced antibiotic efficacy against $P$. aeruginosa $\mathrm{PAO} 1$ persister cells in an electrochemical system applying $\sim 70 \mu \mathrm{A} / \mathrm{cm}^{2} \mathrm{DC}{ }^{16}$ Under this condition, it is likely that SS304 corroded and released iron ions. ${ }^{21} \mathrm{~A}$ similar increased efficacy of antibiotic was reported

\footnotetext{
${ }^{1}$ The Gene and Linda Voiland School of Chemical Engineering and Bioengineering, Washington State University, Pullman, WA 99163 , USA and ${ }^{2}$ Paul G Allen School for Global Animal Health, Washington State University, Pullman, WA 99163, USA.

Correspondence: Haluk Beyenal (beyenal@wsu.edu)
}

Received: 25 April 2016 Revised: 23 July 2016 Accepted: 8 August 2016

Published online: 23 November 2016 
when an inert carbon electrode under the same applied DC was used against $P$. aeruginosa PAO1 persister cells in the same system. ${ }^{22}$ An inert carbon electrode does not release metal cations as SS304 does; thus, the release of metal cations is unlikely to be the mechanism for the efficacy of a combination of DC and antibiotic treatment. ${ }^{22}$ The authors speculated that electrochemically generated reactive oxygen species (ROS) (e.g., $\mathrm{H}_{2} \mathrm{O}_{2}$ and $\mathrm{OH} \bullet$ ) were responsible for this effect, but they did not confirm this experimentally. ${ }^{22}$

An e-scaffold generates $\mathrm{H}_{2} \mathrm{O}_{2}$, which enters the bacterial periplasm through porins, ${ }^{23,24}$ where it can induce intracellular production of highly reactive hydroxyl free radicals $(\mathrm{OH} \bullet)^{25,26}$ that degrade membrane lipids, proteins, and DNA. ${ }^{26,27}$ Recent research also found that $\mathrm{H}_{2} \mathrm{O}_{2}$ eliminates some of the persister cells in biofilms, facilitates the disruption of biofilm architecture and mediates the generation of metabolically active dispersal cells in a range of Gram-negative bacterial biofilms. ${ }^{28,29}$ Such metabolic activity in surviving dispersal cells and $\mathrm{OH} \cdot$ production have been reported to induce bacterial sensitivity to antibiotic treatment. ${ }^{30-32}$ Therefore, e-scaffold generated $\mathrm{H}_{2} \mathrm{O}_{2}$ possibly promotes intracellular $\mathrm{OH}$ - production that in turn improves antibiotic sensitivity in biofilms and attacks persister cells.

In this work, we used $P$. aeruginosa PAO1 with an aminoglycoside antibiotic (tobramycin). $P$. aeruginosa PAO1 can resist tobramycin by producing periplasmic glucans, mutations of ribosome-binding sites or increased efflux pump action inhibiting cellular uptake. $^{33}$ Furthermore, $P$. aeruginosa PAO1 biofilm persister cells are reportedly less sensitive to tobramycin. ${ }^{9}$ We isolated persister cells from $P$. aeruginosa PAO1 biofilms after treating them with ciprofloxacin following published protocols. ${ }^{16,34}$ We hypothesized that the bacterial subpopulation that survived e-scaffold generated $\mathrm{H}_{2} \mathrm{O}_{2}$ would be more sensitive to tobramycin than these ciprofloxacin-tolerant persister cells. The objectives of this study were (1) to evaluate the tobramycin susceptibility of $P$. aeruginosa PAO1 biofilms treated with an, e-scaffold and compare it with the tobramycin susceptibility of persister cells, (2) to evaluate the efficacy of the e-scaffold against persister cells and (3) to determine whether e-scaffold treatment would increase intracellular production of $\mathrm{OH} \cdot$ radicals and increase membrane permeability in the bacterial cells, making them more susceptible to antibiotics. In addition, change in bacterial cell morphology after e-scaffold treatment was observed using scanning electron microscopy (SEM). Finally, based on these observations, a possible mechanism of e-scaffold enhanced antibiotic susceptibility is proposed and a future mechanistic study is suggested.

\section{RESULTS}

Electrochemical scaffold enhances tobramycin susceptibility in biofilm cells

When biofilm treatments were combined with different concentrations of tobramycin, the surviving cells responded differently. The tobramycin susceptibility of $P$. aeruginosa PAO1 biofilms regrown from fresh culture, untreated biofilm cells, and persister cells isolated from biofilms appeared to follow a dose response at tested concentrations between 0 and $40 \mu \mathrm{g} / \mathrm{ml}$ (Fig. 1). The biofilms regrown from persister cells showed tolerance to tobramycin, with only a $(1.2 \pm 0.16)$-log reduction in viable cells for $10 \mu \mathrm{g} / \mathrm{ml}$ tobramycin and no further significant decrease at higher concentrations. These persister cells had the same minimum inhibitory concentration (MIC) as the fresh culture (Supplementary information); however, consistent with the characteristic behavior of "persister cells", they survived antibiotic treatment, regrew and developed tolerance to tobramycin identical to their regular population. ${ }^{1,35}$ Interestingly, tobramycin tolerance was observed in biofilms regrown from untreated

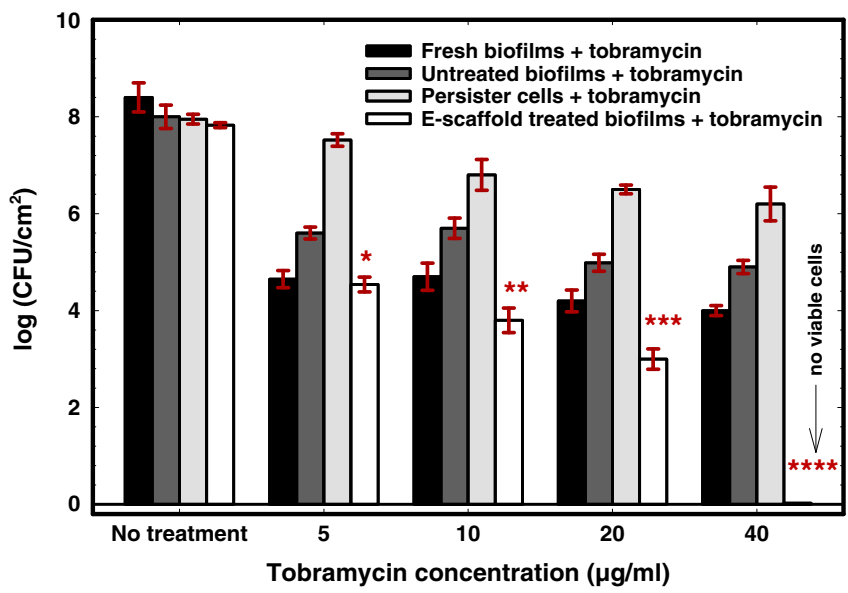

Fig. 1 E-scaffold enhances tobramycin susceptibility in $P$. aeruginosa PAO1 biofilms. Bars represent means of logarithms of colonyforming units of viable biofilm cells. Error bars represent the standard error of the means from three biological replicates. The symbols $*, * *, * * *$, and $* * * *$ represent significant differences in tobramycin susceptibility between e-scaffold treated biofilms + tobramycin and untreated biofilms + tobramycin $(n=3, *, P=0.002$; $*^{*},{ }^{* * *},{ }^{* * *} P \leq 0.001$; paired $t$-test)

biofilm cells and persister cells isolated from biofilms. In contrast, no tolerance to tobramycin was identified for biofilms regrown from e-scaffold treated cells when different concentrations of tobramycin were combined with e-scaffold treatment (Fig. 1). This confirms the prevention of persistence by the e-scaffold. A linear dose response was observed for the log reduction of e-scaffold treated biofilm cells which received tobramycin treatment, leading to a complete eradication at $40 \mu \mathrm{g} / \mathrm{ml}$ tobramycin (Fig. 1). This concentration $(20 \times \mathrm{MIC})$ is still considerably lower than what is typically required for $P$. aeruginosa PAO1 biofilm treatment with tobramycin ( $>500 \times$ of MIC) as reported in the literature. ${ }^{36}$ Overall, a significant increase in tobramycin susceptibility was attained for e-scaffold treated biofilms compared to biofilms that were not treated with an e-scaffold ( $P<0.05$, paired t-tests) (Fig. 1). Among the tested tobramycin concentrations, we observed a maximum tobramycin susceptibility at $40 \mu \mathrm{g} / \mathrm{ml}$ in e-scaffold treated biofilms compared to that for persister cells.

\section{Electrochemical scaffold eradicates persister cells}

The effect of e-scaffold generated $\mathrm{H}_{2} \mathrm{O}_{2}$ on P. aeruginosa PAO1 persister cells isolated from ciprofloxacin-treated biofilms was explored. As Fig. 2 shows, $\sim 0.31 \%$ of the total biofilm cells belonged to the persister population, which is in the range reported in the literature. ${ }^{37}$ Within $6 \mathrm{~h}$ of these persister cells being treated with an e-scaffold, no viable persister cells were apparent. This corresponds to a 5-log reduction in persistence compared to the control initial persister cells $(P \leq 0.001$, one-way ANOVA followed by Bonferroni test). No growth was observed even after the treated cells were exposed to fresh medium alone for $24 \mathrm{~h}$ upon removal of the e-scaffold. This confirmed complete eradication of persister cells by e-scaffold treatment. In contrast, the final population of persister cells did not change within the additional $6 \mathrm{~h}$ of ciprofloxacin treatment. The e-scaffold was also found to be effective against total biofilm cells, with $(4.2 \pm 0.23)$ and $(4.95 \pm 0.20)$-log reductions in viable cells within 6 and $24 \mathrm{~h}$ of treatment, respectively, compared to the control final biofilm cells. Together these results suggest that the e-scaffold is effective against both regular biofilm cells in active states and persister cells in inactive metabolic states. They also confirm that persister 
cells are inherently more sensitive to e-scaffold generated $\mathrm{H}_{2} \mathrm{O}_{2}$ exposure.

E-scaffold induces $\mathrm{OH} \cdot$ generation and increases membrane permeability

We observed increased fluorescence for both e-scaffold treated and exogenous $\mathrm{H}_{2} \mathrm{O}_{2}$ treated biofilm cells, indicating enhanced $\mathrm{OH}$ - formation after e-scaffold generated $\mathrm{H}_{2} \mathrm{O}_{2}$ treatment (Fig. 3a). Furthermore, an increase in the propidium iodide (PI) fluorescence of e-scaffold treated cells was observed compared to untreated biofilm cells (Fig. 3b). PI is a membrane-impermeable dye and can only enter a bacterial cell if the outer membrane is damaged. It can permeate the cytoplasm and bind to the DNA, showing an increased fluorescence intensity, only upon disruption of the cell

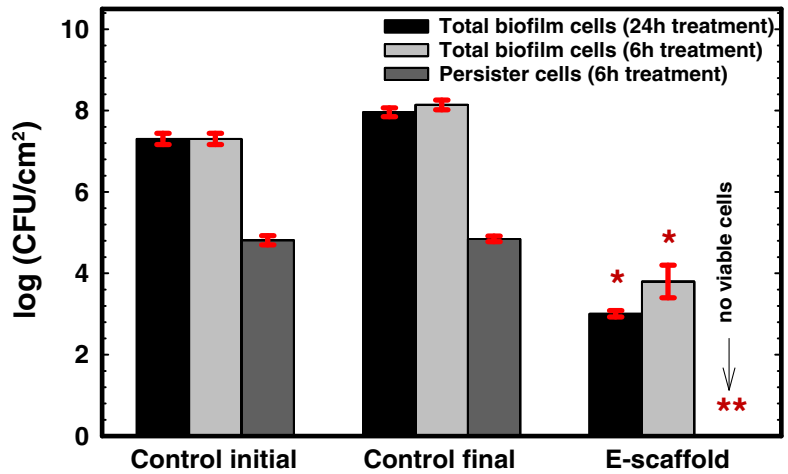

Fig. 2 Exposure to e-scaffold eradicates the persister cells in $P$. aeruginosa PAO1 biofilms. Bars represent means of logarithms of colony-forming units of viable biofilm cells. Error bars represent the standard errors of the means from three biological replicates. The symbol * denotes a significant difference compared to total biofilm cells ( $n=3, P<0.05$, one-way ANOVA), and ** denotes a significant difference compared to control initial persister cells $(n=3, P<0.001$, one-way ANOVA) membranes by the e-scaffold. ${ }^{22,38}$ Thus, an increase in $\mathrm{Pl}$ intensity corresponds to an increased membrane permeability. Figure $3 b$ shows that PI permeability increased in e-scaffold treated cells, indicating possible damage to the outer cell membrane by the e-scaffold. Increased membrane permeability was additionally verified using 3,3'-dipropylthiacarbocyanine iodide, a membrane potential sensitive dye. An increase in the fluorescence intensity of 3,3'-dipropylthiacarbocyanine iodide was observed in e-scaffold treated cells compared to untreated biofilm cells (Fig. 3c), indicating membrane depolarization after exposure to e-scaffold. The dissipation of the membrane potential may be caused by the perturbation of the membrane lipid bilayers. ${ }^{39}$ Membrane potential sensitive dye 3,3'-dipropylthiacarbocyanine iodide enters only depolarized cells, where it binds reversibly to lipid-rich intracellular components. ${ }^{40}$ The increased fluorescence intensity of this dye in e-scaffold treated cells (Fig. 3c) indicates that the e-scaffold disrupted the cytoplasmic membrane and that this induced depolarization of the plasma membrane potential. Thus Fig. 3 suggests that the e-scaffold increased membrane permeability, possibly upon the membrane integrity of the cells being compromised by $\mathrm{OH} \cdot$.

Additionally, membrane-compromised cells similar to those in exogenous $\mathrm{H}_{2} \mathrm{O}_{2}$ treated samples were observed in e-scaffold treated samples in SEM images (Fig. 4). Similar deformation was observed previously by Istanbullu et al. in cells treated with electrochemically generated $\mathrm{H}_{2} \mathrm{O}_{2}{ }^{18}$ and by DeQueiroz et al. and Diao et al. in cells treated with exogenous $\mathrm{H}_{2} \mathrm{O}_{2}$. ${ }^{41}$ Untreated biofilm cells showed intact cell walls and membranes (Fig. 4). Thus, Fig. 4 indicates e-scaffold generated $\mathrm{H}_{2} \mathrm{O}_{2}$ induced morphological changes in cells and structural damage of the outer membrane that might increase membrane permeability. ${ }^{42,43}$

\section{DISCUSSION}

Electrochemical method combined with antibiotic has been suggested to be effective against biofilms in several previous studies, yet the mechanism behind this increased antibiotic efficacy remains unclear. ${ }^{15,44}$ In this work, an e-scaffold that
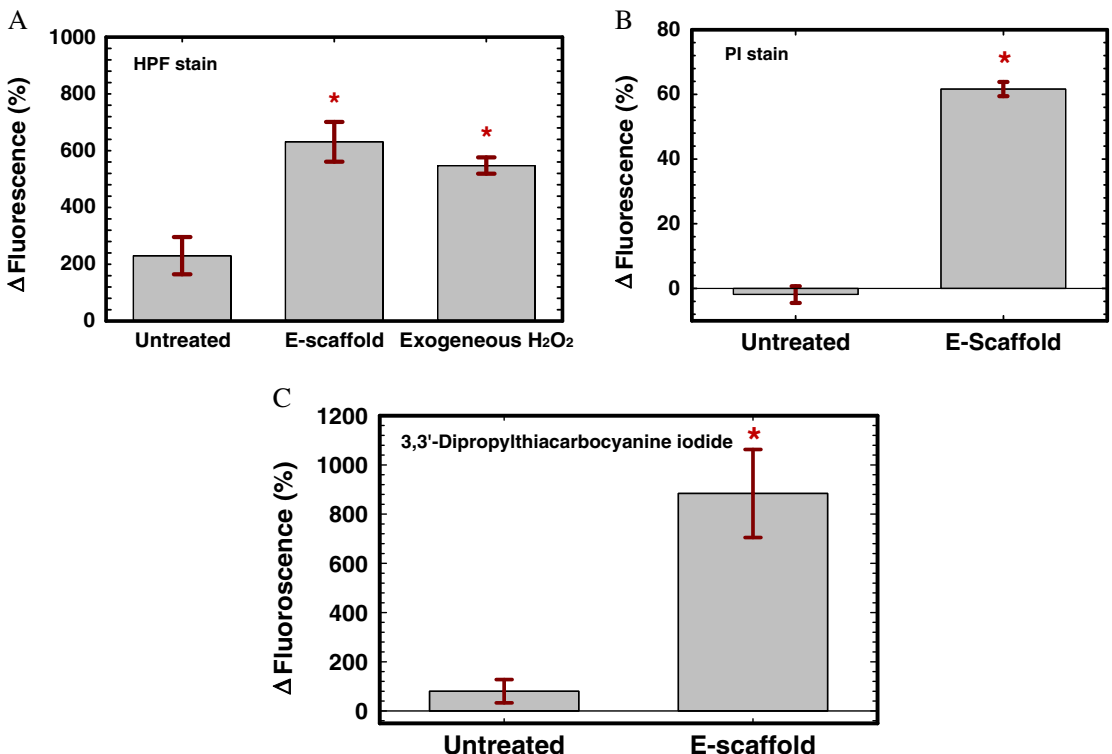

Fig. 3 E-scaffold increases $\mathrm{OH} \bullet$ formation and membrane permeability. a Increase in fluorescence of HPF-stained e-scaffold treated and exogenous $\mathrm{H}_{2} \mathrm{O}_{2}$ treated $P$. aeruginosa PAO1 biofilm cells indicates increased $\mathrm{OH} \bullet$ formation compared to untreated biofilms. $\mathbf{b}$ Increase in fluorescence of propidium iodide (PI) indicates increased membrane permeability of $P$. aeruginosa PAO1 cells after exposure to e-scaffold. c Increase in fluorescence of 3, 3'-dipropylthiacarbocyanine iodide, a membrane potential sensitive dye, in e-scaffold treated $P$. aeruginosa PAO1 cells verifies bacterial membrane depolarization by e-scaffold resulting in increased membrane permeability. Error bars represent standard errors of means for at least three biological replicates. The symbol * indicates a significant difference from the untreated biofilm cells $(n=3, P<0.001$; paired $t$-test) 


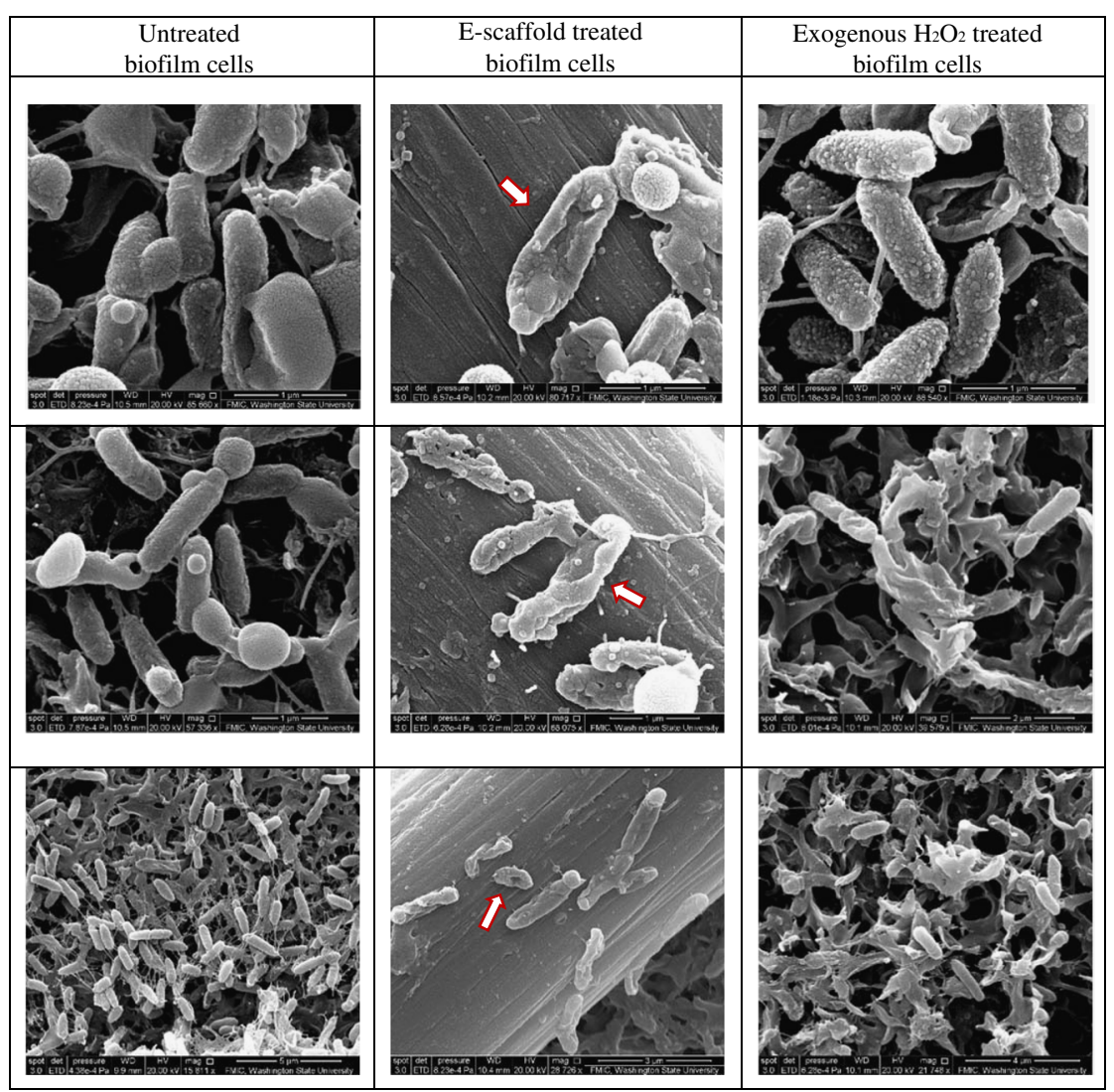

Fig. 4 Scanning electron microscopy (SEM) images showing untreated, e-scaffold treated and exogenous $\mathrm{H}_{2} \mathrm{O}_{2}$ treated P. aeruginosa PAO1 biofilm cells. Three representative images are shown for each treatment. Red arrows indicate cells showing a stressed membrane

electrochemically generates a constant concentration $\mathrm{H}_{2} \mathrm{O}_{2}$ was investigated as a mean of enhancing antibiotic efficacy against biofilm cells and its efficacy against ciprofloxacin-tolerant persister cells was evaluated. Overall, our results indicate that the e-scaffold induced intracellular formation of $\mathrm{OH} \cdot$ and improved membrane permeability. These mechanisms enhanced tobramycin efficacy, including against persister cells.

The biofilm removal mechanism of e-scaffolds is electrochemical generation of $\mathrm{H}_{2} \mathrm{O}_{2}$, which is a potential biocide and oxidizing agent. ${ }^{17} \mathrm{H}_{2} \mathrm{O}_{2}$ mediates dispersal in biofilms, disrupts various bacterial processes and cellular networks, and disrupts the cell envelope through intracellular production of ROS such as $\mathrm{OH}$. in Gram-negative bacteria, as shown in Fig. 5.26,28,45 Our observations suggest that e-scaffold generated $\mathrm{H}_{2} \mathrm{O}_{2}$ increases intracellular $\mathrm{OH} \cdot$ formation in Gram-negative $P$. aeruginosa PAO1 biofilm cells. Furthermore, in membrane permeability assays and SEM image analysis, we observed increased permeability with moderate membrane damage in cells after e-scaffold treatment. Thus, we propose that when e-scaffold generated $\mathrm{H}_{2} \mathrm{O}_{2}$ enters a bacterial cell, it induces intracellular ROS production such as $\mathrm{OH} \cdot$, which can increase the permeability of bacterial membranes. ${ }^{26,27}$ Increased permeability can facilitate better antibiotic penetration. These effects can potentiate the tobramycin susceptibility of $P$. aeruginosa PAO1 biofilms and eradicate persister cells in various metabolic states. ${ }^{31,46}$

That the e-scaffold increases the permeability of the outer membrane of Gram-negative bacteria opens up the possibility of enhancing susceptibility to a range of antibiotics. As noted above, recent papers questioned the role of electric current in electrochemically generating $\mathrm{H}_{2} \mathrm{O}_{2}$ that enhanced antibiotic susceptibility in biofilms and associated persister cells. ${ }^{15,22,47}$ It has already been confirmed that an e-scaffold at a constant applied potential $\left(-600 \mathrm{mV}_{\mathrm{Ag} / \mathrm{AgCl}}\right)$ electrochemically generates $\mathrm{H}_{2} \mathrm{O}_{2}$, which is the mechanism of action for biofilm removal. ${ }^{17}$ Here, we explained that e-scaffold generated $\mathrm{H}_{2} \mathrm{O}_{2}$ can lead to intracellular $\mathrm{OH}$. production in bacteria that possibly enhances the efficacy of tobramycin against $P$. aeruginosa PAO1 biofilms and thus eradicates biofilms and associated persister cells.

The observed effect of increased intracellular $\mathrm{OH} \bullet$ formation as a possible mechanism for enhanced antibiotic susceptibility in bacteria needs to be further confirmed by more mechanistic studies. For instance, decreasing $\mathrm{OH} \cdot$ through the addition of thiourea $(150 \mathrm{mM})$, an $\mathrm{OH} \cdot$ scavenger, $^{48}$ inhibited bacterial cell death due to e-scaffold and tobramycin (Fig. S2, Supplementary information), indicating that $\mathrm{OH} \cdot$ production may be critical for the observed bactericidal activity. Additionally, overexpression of cellular ROS scavengers such as superoxide dismutase (SOD) can be used to inhibit e-scaffold induced $\mathrm{OH} \cdot$ formation and bacterial cell death. Thus, it can be verified whether $\mathrm{OH}$ - formation is a critical factor for the observed bacterial killing by e-scaffold and tobramycin. As indicated in Fig. 5, $\mathrm{OH} \cdot$ formation occurs through the Fenton reaction and $\mathrm{Fe}^{2+}$ plays a vital role in this reaction. Testing the efficacy of e-scaffold and tobramycin against mutant strains with impaired iron regulation would be another way to confirm $\mathrm{OH}$. formation as the fundamental mechanism for escaffold enhanced antibiotic susceptibility. ${ }^{38}$

Finally, this research proposes future use of the e-scaffold as an effective individual or adjuvant therapy against persistent biofilm infections. Notably, the application of AC and DC electric fields combined with antibiotics involves a different mechanism ${ }^{49}$ than that of the electrochemical biofilm control method proposed in this work. 


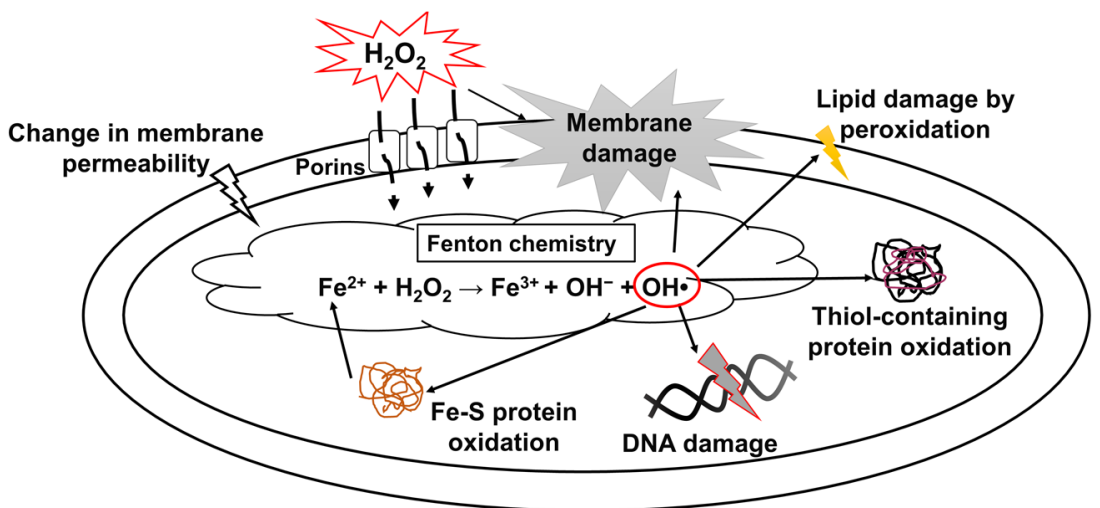

Fig. 5 Proposed mechanism for e-scaffold generated $\mathrm{H}_{2} \mathrm{O}_{2}$ enhancing antibiotic susceptibility. $\mathrm{H}_{2} \mathrm{O}_{2}$ generated extracellularly by e-scaffold diffuses through the bacterial cell envelope and reacts with intracellular $\mathrm{Fe}^{2+}$, forming radicals that oxidize lipids, proteins and DNA, which prompts cell death. Through membrane damage or changing membrane permeability, antibiotic penetration into the bacterial cell is increased, which in turn enhances the antibiotic susceptibility of the cells

\section{MATERIALS AND METHODS}

Growth medium, chemicals, and antibiotics

For all experiments, $20 \mathrm{~g} / \mathrm{L}(1 \times)$ Luria broth (LB) medium (Sigma-Aldrich, catalog \#L3522) was used to grow overnight $P$. aeruginosa PAO1 cultures and $1 \mathrm{~g} / \mathrm{L}(0.05 \times)$ LB was used as the growth medium for biofilms. Tobramycin (Sigma Aldrich, catalog \#T4014) and ciprofloxacin (Sigma Aldrich, catalog \#17850) solutions were diluted in $1 \mathrm{~g} / \mathrm{L}(0.05 \times)$ LB for antibiotic susceptibility experiments and persister cell isolation, respectively. Minimum inhibitory concentrations (MICs) were determined for both antibiotics following the Clinical and Laboratory Standards Institute (CLSI) protocol as detailed in Supplementary information. ${ }^{50}$ Other key compounds included 3'-p-hydroxyphenyl fluorescein dye (Invitrogen, catalog \#H36004), propidium iodide (Invitrogen, catalog \#L-7012), 3, 3'-dipropylthiacarbocyanine iodide (Sigma Aldrich, catalog \#318434), thiourea (AK Scientific, Inc., catalog \#S726) and $\mathrm{H}_{2} \mathrm{O}_{2}$ (VWR, catalog \#RC3819-16).

\section{Culture and biofilm preparation}

Frozen stocks of $P$. aeruginosa PAO1 were cultured overnight in LB at $37^{\circ} \mathrm{C}$ on a rotating table $(70 \mathrm{rpm})$. For biofilm experiments, overnight culture was adjusted to $\mathrm{OD}_{600} \approx 0.5$ in $\mathrm{LB}$ and used as inoculum. ${ }^{17}$ Briefly, $2 \mathrm{ml}$ of culture was used to inoculate sterile glass bottom petri dishes (MatTek Corporation, catalog \#P35G-1.5-20-C) and allowed to form biofilms for $24 \mathrm{~h}$. These one-day-old biofilms were treated with e-scaffolds for $24 \mathrm{~h}$, as described previously. ${ }^{17}$ Briefly, untreated and e-scaffold treated biofilm cells were washed twice to remove loosely attached cells and then remaining cells were recovered for antibiotic susceptibility testing. To identify and isolate $P$. aeruginosa PAO1 persister cells, planktonic culture was grown to the stationary phase and the dose-dependent killing curve for ciprofloxacin $(0-200 \mu \mathrm{g} / \mathrm{mL}$ ) was investigated (Supplementary information, Fig. S1). ${ }^{34}$ A plateau of the surviving subpopulation was observed for ciprofloxacin concentrations above $50 \mu \mathrm{g} / \mathrm{mL}$ (200x of MIC), and these were identified as persister cells. ${ }^{34,51}$ We assessed the antibiotic treatment on biofilms from three different populations: cells recovered after no treatment ("untreated biofilms"), cells recovered after e-scaffold treatment ("e-scaffold treated biofilm") and "persister cells" that were isolated from biofilms treated with $200 \mu \mathrm{g} / \mathrm{mL}$ ciprofloxacin for $3.5 \mathrm{~h}$ according to a published protocol. ${ }^{34}$ For experiments with persister cells, the ciprofloxacin-treated biofilms were washed and refreshed with $0.9 \% \mathrm{NaCl}$ for subsequent experiments. This method for culture, biofilm preparation and treatments is illustrated in Fig. 6.

\section{Biofilm treatment with e-scaffold}

$P$. aeruginosa PAO1 biofilms were exposed to e-scaffold treatment for $24 \mathrm{~h}$, as described previously. ${ }^{17}$ Briefly, a custom-built e-scaffold was fabricated using carbon fabric as detailed in Supplementary information. ${ }^{17}$ Biofilms were carefully washed $(2 \times)$ with LB $(0.05 \times)$ and an e-scaffold was overlaid onto the biofilms followed by $4 \mathrm{~mL}$ of fresh medium. A standard $\mathrm{Ag} / \mathrm{AgCl}$ (saturated $\mathrm{KCl}$ ) reference electrode was introduced to apply a constant potential $\left(-600 \mathrm{mV}_{\mathrm{Ag} / \mathrm{Agcl}}\right)$ to an e-scaffold using a Gamry Series $\mathrm{G} 300$ potentiostat (Gamry Instruments, Warminster, PA, USA) to reduce oxygen, generate a low concentration of $\mathrm{H}_{2} \mathrm{O}_{2}$ and deliver it continuously to the biofilms (Fig. 6a). After treatment, the viable cell counts were determined using a modified drop-plate cell counting method. ${ }^{17,52}$ Loosely attached cells were removed by carefully washing the biofilms with $0.9 \% \mathrm{NaCl}$ before they were resuspended in $5 \mathrm{~mL}$ of $0.9 \% \mathrm{NaCl}$ and vortexed for $30 \mathrm{~s}$. These suspensions were centrifuged $(4180 \times \mathrm{g}$ for $10 \mathrm{~min})$, and the resulting cell pellet was resuspended in $1 \mathrm{~mL}$ of $0.9 \% \mathrm{NaCl}$. Aliquots $(250 \mu \mathrm{L})$ were then serially diluted, and $10 \mu \mathrm{L}$ of each dilution was plated onto LB agar. Plates were incubated for $24 \mathrm{~h}\left(37^{\circ} \mathrm{C}\right)$, and colony-forming units (CFU) were enumerated.

Tobramycin susceptibility of e-scaffold treated cells

To determine whether e-scaffold treatment altered susceptibility to antibiotics, ${ }^{35}$ biofilm treatments were combined with tobramycin treatments. For this experiment, the recovered biofilm cells were harvested (Fig. $6 \mathrm{~b}$ ) and adjusted to $\mathrm{OD}_{600} \approx 0.5$ in $\mathrm{LB}$ medium $(0.05 \times)$. A $1-\mathrm{mL}$ cell suspension was used to inoculate a 24-well plate, where biofilms were allowed to form. Biofilms were treated with an e-scaffold for $2 \mathrm{~h}$. Each well was then washed $(2 \times)$ and challenged with $1 \mathrm{~mL}$ of one of the test concentrations $(5,10,20$ and $40 \mu \mathrm{g} / \mathrm{mL})$ of tobramycin for $6 \mathrm{~h}$. After treatment, the cells were washed $(2 \times)$, resuspended in $0.9 \% \mathrm{NaCl}$ and processed to enumerate $\mathrm{CFU}^{52}$ Cell counts were compared for e-scaffold and other treated and untreated biofilms. The treatments are summarized in Fig. 6b.

Effect of e-scaffold on persister cells

Biofilms were grown for $24 \mathrm{~h}$ in 6-well plates and treated with $200 \mu \mathrm{g} / \mathrm{mL}$ ciprofloxacin for $3.5 \mathrm{~h}$ to isolate persister cells from ciprofloxacin-treated biofilms. ${ }^{16}$ The total number of viable cells was determined for ciprofloxacin-treated and untreated biofilms using the modified dropplate cell counting method. ${ }^{52}$ Remaining persister cells were then exposed to either $200 \mu \mathrm{g} / \mathrm{ml}$ ciprofloxacin or e-scaffold treatment for $6 \mathrm{~h}$ (in the $0.9 \% \mathrm{NaCl}$ solution). Final CFU numbers were then determined following the procedure described above. Figure $6 c$ summarizes the treatment methodology we used.

\section{Hydroxyl free radical detection assay}

Intracellular hydroxyl free radical $\left(\mathrm{OH}^{\circ}\right)$ formation was detected using $5 \mu \mathrm{M}$ of a fluorescent reporter dye, $3^{\prime}$-(p-hydroxyphenyl fluorescein) (HPF) (Invitrogen, catalog $\# \mathrm{H} 36004)$ following a published protocol. ${ }^{38}$ Briefly, e-scaffold treated, exogenous $\mathrm{H}_{2} \mathrm{O}_{2}$-treated and untreated biofilm cells were vortexed in $500 \mu \mathrm{L}$ of $\mathrm{LB}$ in a microcentrifuge tube for $30 \mathrm{~s}$. These samples were centrifuged $(10,000 \times g$ for $10 \mathrm{~min})$, and then the medium was replaced with a final concentration of $5 \mu \mathrm{M} \mathrm{HPF}$ prepared in $500 \mu \mathrm{L}$ of $0.1 \mathrm{M}$ PBS. After staining in the dark at room temperature for $15 \mathrm{~min}$, samples were centrifuged at $10,000 \times g$ for $10 \mathrm{~min}$. Supernatant was removed, and cells were rinsed and resuspended with PBS. An aliquot 


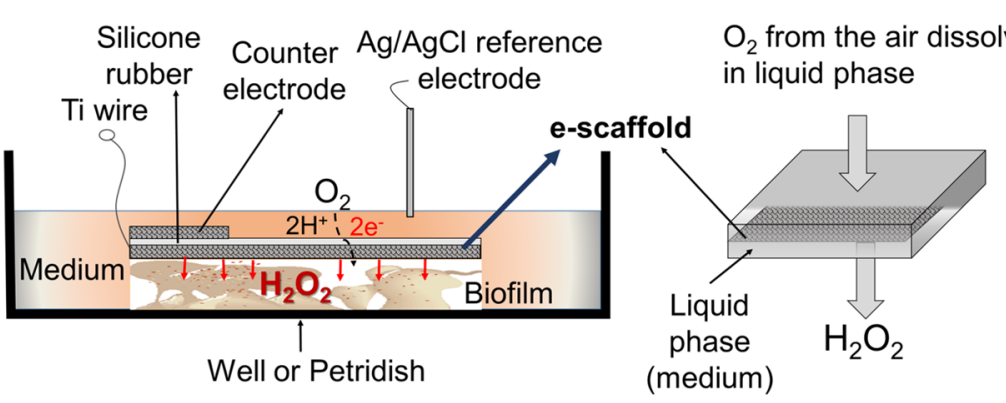

\section{A. Experimental setup for treating biofilms with e-scaffold}

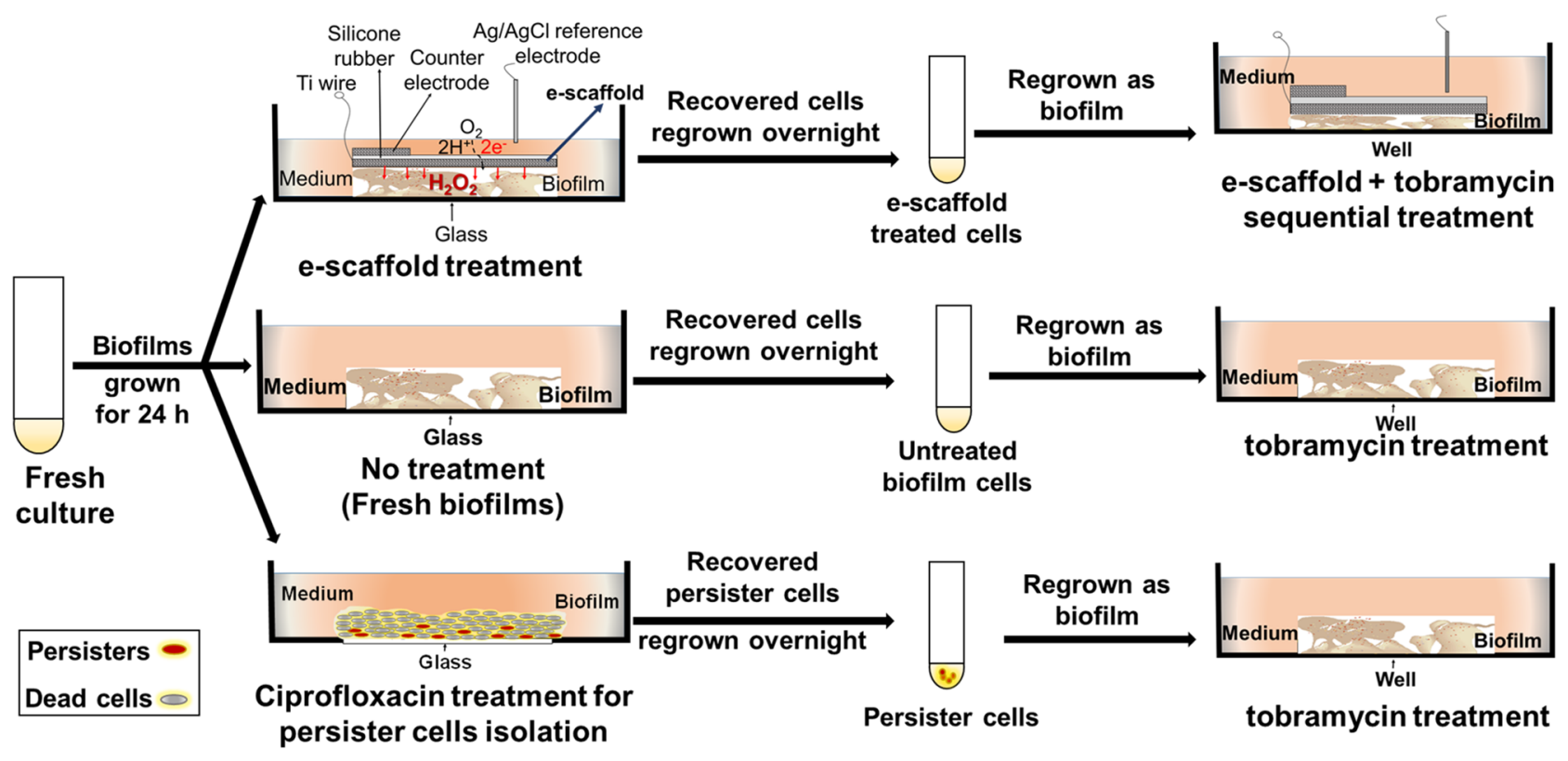

\section{B. Recovered biofilm cells treated with e-scaffold and tobramycin}

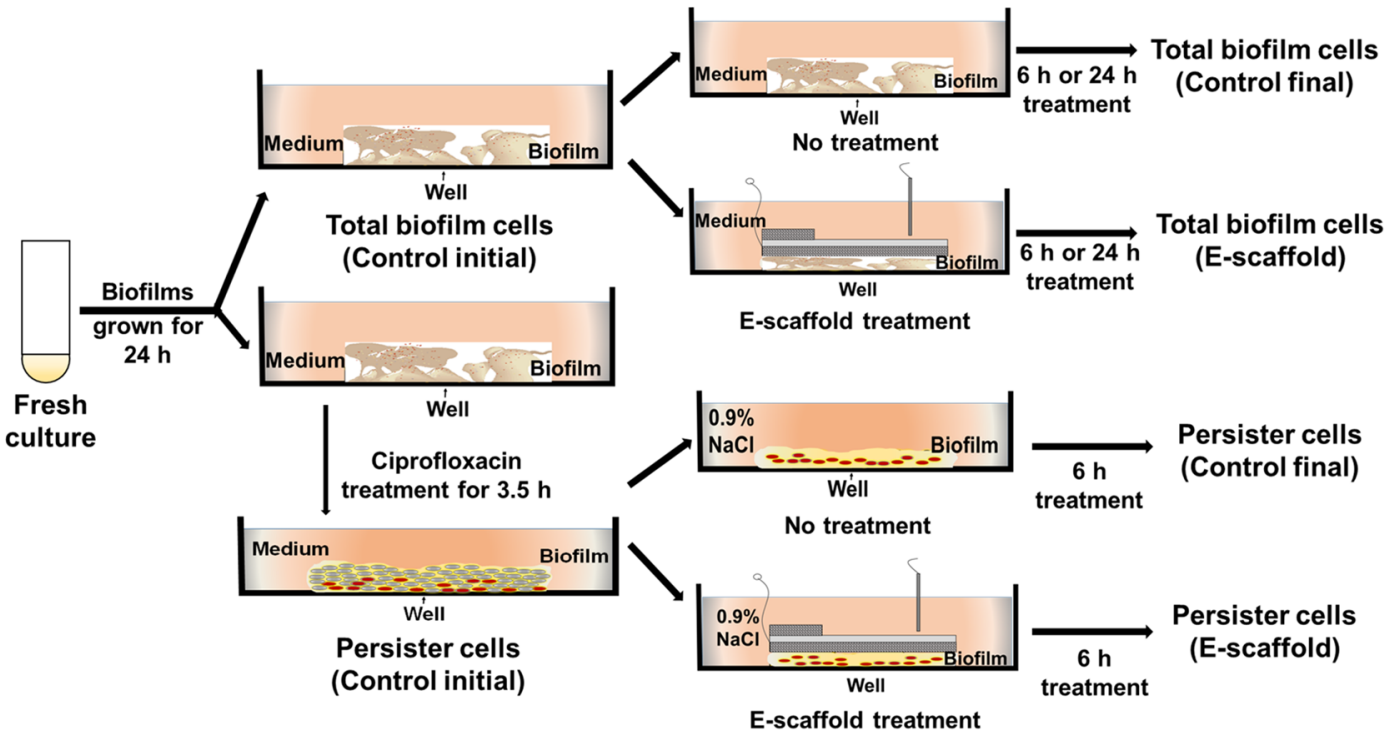

\section{Treatment of biofilms and isolated persister cells with e-scaffold}

Fig. 6 a Schematic of experimental setup for the treatment of biofilm exposed to an e-scaffold with an illustration of electrochemical $\mathrm{H}_{2} \mathrm{O}_{2}$ production. The electrodes are connected to a potentiostat (not shown in figure). Scientific Reports, 2015. 5, 14908. DOI: 10.1038/srep14908. (c) Creative Commons Attribution 4.0 International License. b Recovered biofilm cells treated with e-scaffold and tobramycin. c Treatment of biofilms and persister cells with e-scaffold 
$(100 \mu \mathrm{L})$ was added to each well in a 96-well plate, and fluorescence intensity was quantified using a microplate reader (Bio-Tek Cytation 5) with excitation at 490 and emission at $515 \mathrm{~nm}$. For the $\mathrm{OH}$. formation assays, fluorescence was estimated as follows: ((Fluorescence with dye-Fluorescence without dye)/(Fluorescence without dye)) $\times(100)$.

\section{Membrane permeability}

Change in bacterial membrane permeability was evaluated by analyzing the influx of a membrane-impermeable dye, propidium iodide $(\mathrm{PI})^{22,38}$ according to the manufacturer's instructions (Invitrogen, catalog \#L-7012). E-scaffold treated and untreated biofilm cells were centrifuged $(6000 \mathrm{rpm}$, 10 mins) to cell pellets and supernatant was poured off. The cell pellets were stained with PI for $15 \mathrm{~min}$ in the dark, then washed twice with $0.9 \%$ $\mathrm{NaCl}$ to remove any unbound dye. Cells were then resuspended in $0.9 \%$ $\mathrm{NaCl}$, and $100 \mu \mathrm{L}$ of each suspension was transferred in triplicate into wells of a 96-well plate. Fluorescence intensity was quantified (excitation 535 $\mathrm{nm}$, emission $517 \mathrm{~nm}$ ). Fluorescence was determined as a percentage change compared to untreated sample using the following formula: ((Fluorescence with dye-Fluorescence without dye)/(Fluorescence without dye) $) \times(100)$.

Additionally, the effect of e-scaffold treatment on bacterial membrane permeability was detected using a membrane potential sensitive dye, 3 , 3'-dipropylthiacarbocyanine iodide. The fluorescence intensity of 3 , 3 '-dipropylthiacarbocyanine iodide changes in response to changes in plasma membrane potential upon structural damage. ${ }^{42,53}$ Untreated biofilm cells were washed and then resuspended in buffer $A(20 \mathrm{mM}$ glucose, $5 \mathrm{mM}$ HEPES, $\mathrm{pH}=7.2$ ) with $0.1 \mathrm{M} \mathrm{KCl}$. To achieve a stable signal, 3,3'-dipropylthiacarbocyanine iodide was added to untreated and e-scaffold treated biofilm cell suspensions and incubated for $10 \mathrm{~min}$. Changes in the fluorescence intensity induced by changes in membrane potential after exposure to e-scaffold were measured at an excitation wavelength of $622 \mathrm{~nm}$ and an emission wavelength of $670 \mathrm{~nm}^{42}$ The measurements were performed in triplicate for three biological replicates in wells of a 96-well plate. Fluorescence was determined as a percentage change compared to untreated sample using the following formula: ((Fluorescence with dye-Fluorescence without dye)/(Fluorescence without dye)) $\times(100)$.

\section{Scanning electron microscopy}

For scanning electron microscopy (SEM) imaging, biofilms were grown for $24 \mathrm{~h}$ on UV-sterilized, $0.22-\mu \mathrm{m}$ type GV membrane filters (Millipore, catalog ID \#551200401) placed in sterile 6-well plates. Exogenous $\mathrm{H}_{2} \mathrm{O}_{2}$ was added continuously at an average $0.008 \mathrm{mmol} / \mathrm{h}$ for $24 \mathrm{~h}$ to mimic the e-scaffold generated $\mathrm{H}_{2} \mathrm{O}_{2}$ treatment described previously. ${ }^{17}$ After treatment for $24 \mathrm{~h}$, both e-scaffolds and membrane filters with biofilms were aseptically collected from the untreated, e-scaffold treated and exogenous $\mathrm{H}_{2} \mathrm{O}_{2}$ treated wells. The membrane filters and e-scaffolds were fixed overnight with $2.5 \%$ glutaraldehyde and $2 \%$ paraformaldehyde in $0.1 \mathrm{M}$ phosphate buffer, followed by rinsing with $0.1 \mathrm{M}$ phosphate buffer ( $3 \times 10 \mathrm{~min}$ each). The membranes and e-scaffolds were then dehydrated gradually by being washed sequentially with $10,30,50,70$, and $95 \%$ alcohol (10 min each) and $100 \%$ alcohol $(3 \times 10 \mathrm{~min}$ each). Hexamethyldisilizane (HMDS) was used for overnight drying. Samples were then sputter-coated with gold prior to field emission in-lens scanning electron microscopy (FEISEM) (FEl 200F) imaging.

\section{Statistical analysis}

All experiments were conducted for at least three biologically independent replicates. Technical replicates were averaged to produce replicate means that were subsequently used for analysis. Mean values were compared within and between groups using one-way ANOVA followed by Bonferroni's post hoc test for individual comparisons. Differences were considered statistically significant if $P<0.05$ (Sigma plot, version 13, Systat Software, Inc., San Jose, CA).

\section{CONCLUSIONS}

In this work, we found that $P$. aeruginosa PAO1 biofilms treated with e-scaffolds do not develop tolerance to tobramycin; thus, e-scaffolds reduce persistence. Our results indicate that the e-scaffold enhances tobramycin susceptibility in P. aeruginosa PAO1 biofilms and eradicates isolated persister cells. This appears to be a promising advantage of the e-scaffold for controlling persister cells. We further showed that the e-scaffold induces intracellular $\mathrm{OH} \cdot$ formation and causes an increase in membrane permeability and moderate morphological changes in the bacterial membrane. We propose these effects as the mechanism by which it enhances tobramycin efficacy. These results demonstrate the potential of the e-scaffold as an alternative to conventional antibiotic treatment or as an adjuvant therapy to enhance antibiotic susceptibility in complex and persistent biofilm infections.

\section{ACKNOWLEDGEMENTS}

The authors would like to thank Phuc Ha for SEM imaging. The authors are also grateful to the Franceschi Microscopy and Imaging Center of Washington State University for the use of their facilities and staff assistance. The authors would like to thank Mia Mae Kiamco for helping in e-scaffold preparation. This research was supported by NSF-CAREER award \#0954186.

\section{AUTHOR CONTRIBUTIONS}

STS developed the hypothesis, designed the experiments, performed all the experiments and contributed to manuscript preparation. DRC contributed to the research plan and manuscript preparation. $\mathrm{HB}$ conceived the idea and contributed to the experimental design and manuscript preparation.

\section{COMPETING INTERESTS}

The authors declare that they have no competing interests.

\section{REFERENCES}

1 Lewis, K. in Annual review of microbiology Vol. 64 (eds Gottesman, S. \& Harwood, C. S.), 357-372 (Annual Reviews, 2010)

2 Flemming, H.-C. \& Wingender, J. The biofilm matrix. Nat. Rev. Microbiol. 8 623-633, doi:10.1038/nrmicro2415 (2010).

3 Stewart, P. S., Grab, L. \& Diemer, J. A. Analysis of biocide transport limitation in an artificial biofilm system. J Appl. Microbiol. 85, 495-500, doi:10.1046/j.13652672.1998.853529.x (1998).

4 Davenport, E. K., Call, D. R. \& Beyenal, H. Differential protection from tobramycin by extracellular polymeric substances from Acinetobacter baumannii and Staphylococcus aureus Biofilms. Antimicrob. Agents Chemother. 58, 4755-4761, doi:10.1128/aac.03071-14 (2014).

5 Poole, K. Stress responses as determinants of antimicrobial resistance in Gramnegative bacteria. Trends Microbiol. 20, 227-234, doi:10.1016/j.tim.2012.02.004 (2012).

6 Marx, D. E. \& Barillo, D. J. Silver in medicine: the basic science. Burns 40, S9-S18 (2014).

7 Daviskas, E., Anderson, S. D., Eberl, S., Chan, H. K. \& Bautovich, G. Inhalation of dry powder mannitol improves clearance of mucus in patients with bronchiectasis. Am. J. of Respir. Crit. Care Med. 159, 1843-1848 (1999).

8 Gurunathan, S. Biologically synthesized silver nanoparticles enhances antibiotic activity against Gram-negative bacteria. J. Ind Eng. Chem. 29, 217-226, doi:10.1016/j.jiec.2015.04.005 (2015).

9 Barraud, N., Buson, A., Jarolimek, W. \& Rice, S. A. Mannitol enhances antibiotic sensitivity of persister bacteria in pseudomonas aeruginosa biofilms. PLOS ONE $\mathbf{8}$, e84220, doi:10.1371/journal.pone.0084220 (2013).

10 Smith, A. W. Biofilms and antibiotic therapy: is there a role for combating bacterial resistance by the use of novel drug delivery systems?. Adv. Drug Deliv. Rev. 57, 1539-1550, doi:10.1016/j.addr.2005.04.007 (2005).

11 Trop, M. et al. Silver coated dressing Acticoat caused raised liver enzymes and argyria-like symptoms in burn patient. J. Trauma Inj. Infect. Crit. Care 60, 648-652, doi:10.1097/01.ta.0000208126.22089.b6 (2006).

12 Percival, S. L., Bowler, P. G. \& Russell, D. Bacterial resistance to silver in wound care. J. Hosp. Infect. 60, 1-7, doi:10.1016/j.jhin.2004.11.014 (2005).

13 Tkachenko, O. \& Karas, J. A. Standardizing an in vitro procedure for the evaluation of the antimicrobial activity of wound dressings and the assessment of three wound dressings. J. Antimicrob. Chemother. 67, 1697-1700, doi:10.1093/jac/dks110 (2012).

14 Dawson, C. C., Intapa, C. \& Jabra-Rizk, M. A. "Persisters": survival at the cellular level. PLoS Pathog 7, e1002121, doi:10.1371/journal.ppat.1002121 (2011).

15 Del Pozo, J. L., Rouse, M. S. \& Patel, R. Bioelectric effect and bacterial biofilms. A systematic review. Int. J. Artif. Organs 31, 786-795 (2008).

16 Niepa, T. H. R., Gilbert, J. L. \& Ren, D. Controlling Pseudomonas aeruginosa persister cells by weak electrochemical currents and synergistic effects with tobramycin. Biomaterials 33, 7356-7365, doi:10.1016/j.biomaterials.2012.06.092 (2012).

17 Sultana, S. T. et al. Electrochemical scaffold generates localized, low concentration of hydrogen peroxide that inhibits bacterial pathogens and biofilms. Sci. Rep. $\mathbf{5}$ 
14908, doi:10.1038/srep14908, http://www.nature.com/articles/srep14908\# supplementary-information (2015).

18 Istanbullu, O., Babauta, J., Hung Duc, N. \& Beyenal, H. Electrochemical biofilm control: mechanism of action. Biofouling 28, 769-778, doi:10.1080/ 08927014.2012.707651 (2012).

19 Stewart, P. S. et al. Effect of catalase on hydrogen peroxide penetration into Pseudomonas aeruginosa biofilms. Appl. Environ. Microbiol. 66, 836-838, doi:10.1128/aem.66.2.836-838.2000 (2000).

20 Nodzo, S., et al. Cathodic voltage-controlled electrical stimulation plus prolonged vancomycin reduce bacterial burden of a titanium implant-associated infection in a rodent model. Clin. Orthp. Relat. Res. 474, 1668-1675 (2016).

21 Lewandowski, Z. \& Beyenal, H. Mechanisms of microbially influenced corrosion. 1-30 (Springer, Berlin, 2008).

22 Niepa, T. H. R. et al. Sensitizing Pseudomonas aeruginosa to antibiotics by electrochemical disruption of membrane functions. Biomaterials 74, 267-279, doi:10.1016/j.biomaterials.2015.10.007 (2016).

23 Bienert, G. P., Schjoerring, J. K. \& Jahn, T. P. Membrane transport of hydrogen peroxide. Biochimica Et Biophysica Acta-Biomembranes 1758, 994-1003, doi:10.1016/j.bbamem.2006.02.015 (2006).

24 Slauch, J. M. How does the oxidative burst of macrophages kill bacteria? Still an open question. Mol Microbiol 80, 580-583, doi:10.1111/j.1365-2958.2011.07612.x (2011).

25 Haber, F. \& Weiss, J. The catalytic decomposition of hydrogen peroxide by iron salts. Proc. R. Soc. Lond. A 147, 332-351, doi:10.1098/rspa.1934.0221 (1934).

26 Imlay, J. A. Pathways of oxidative damage. Annu. Rev. Microbiol. 57, 395-418, doi:10.1146/annurev.micro.57.030502.090938 (2003).

27 Seaver, L. C. \& Imlay, J. A. Hydrogen peroxide fluxes and compartmentalization inside growing Escherichia coli. J. Bacteriol. 183, 7182-7189, doi:10.1128/ JB.183.24.7182-7189.2001 (2001).

28 Mai-Prochnow, A. et al. Hydrogen peroxide linked to lysine oxidase activity facilitates biofilm differentiation and dispersal in several gram-negative bacteria. J. Bacteriol. 190, 5493-5501, doi:10.1128/jb.00549-08 (2008).

29 Stewart, P. S., Wattanakaroon, W., Goodrum, L., Fortun, S. M. \& McLeod, B. R. Electrolytic generation of oxygen partially explains electrical enhancement of tobramycin efficacy against Pseudomonas aeruginosa biofilm. Antimicrob. Agents Chemother. 43, 292-296 (1999).

30 Dwyer, D. J., Kohanski, M. A. \& Collins, J. J. Role of reactive oxygen species in antibiotic action and resistance. Curr. Opin. Microbiol. 12, 482-489, doi:10.1016/j. mib.2009.06.018 (2009).

31 Grant, S. S., Kaufmann, B. B., Chand, N. S., Haseley, N. \& Hung, D. T. Eradication of bacterial persisters with antibiotic-generated hydroxyl radicals. Proc. Natl. Acad. Sci. USA. 109, 12147-12152, doi:10.1073/pnas.1203735109 (2012).

32 Stewart, P. S., Rayner, J., Roe, F. \& Rees, W. M. Biofilm penetration and disinfection efficacy of alkaline hypochlorite and chlorosulfamates. J. Appl Microbiol. 91, 525-532, doi:10.1046/j.1365-2672.2001.01413.x (2001).

33 Poole, K., Russell, A. D. \& Lambert, P. A. Mechanisms of antimicrobial resistance: opportunities for new targeted therapies. Adv. Drug Deliv. Rev. 57, 1443-1445, doi:10.1016/j.addr.2005.05.001 (2005).

34 Möker, N., Dean, C. R. \& Tao, J. Pseudomonas aeruginosa increases formation of multidrug-tolerant persister cells in response to quorum-sensing signaling molecules. J. Bacteriol. 192, 1946-1955, doi:10.1128/JB.01231-09 (2010).

35 Mulcahy, L. R., Burns, J. L., Lory, S. \& Lewis, K. Emergence of Pseudomonas aeruginosa strains producing high levels of persister cells in patients with cystic fibrosis. J. Bacteriol. 192, 6191-6199, doi:10.1128/jb.01651-09 (2010).

36 Rosenfeld, M. et al. Serum and lower respiratory tract drug concentrations after tobramycin inhalation in young children with cystic fibrosis. J. Pediatr. 139, 572-577, doi:10.1067/mpd.2001.117785 (2001).

37 Spoering, A. L. \& Lewis, K. Biofilms and planktonic cells of Pseudomonas aeruginosa have similar resistance to killing by antimicrobials. J. Bacteriol. 183, 6746-6751, doi:10.1128/jb.183.23.6746-6751.2001 (2001).

38 Morones-Ramirez, J. R., Winkler, J. A., Spina, C. S. \& Collins, J. J. Silver enhances antibiotic activity against gram-negative bacteria. Sci. Transl. Med. 5, 11, doi:10.1126/scitransImed.3006276 (2013).
39 Wu, M. H., Maier, E., Benz, R. \& Hancock, R. E. W. Mechanism of interaction of different classes of cationic antimicrobial peptides with planar bilayers and with the cytoplasmic membrane of Escherichia coli. Biochemistry 38, 7235-7242, doi:10.1021/bi9826299 (1999).

40 Tanaka, M. et al. Cytochrome P-450 metabolites but not NO, PGI2, and $\mathrm{H} 2 \mathrm{O} 2$ contribute to ACh-induced hyperpolarization of pressurized canine coronary microvessels. Am. J. Physiol.- Heart Circ. Physiol. 285, H1939-H1948 (2003).

41 Diao, H. F., Li, X. Y., Gu, J. D., Shi, H. C. \& Xie, Z. M. Electron microscopic investigation of the bactericidal action of electrochemical disinfection in comparison with chlorination, ozonation and Fenton reaction. Process Biochem. 39, 1421-1426, doi:10.1016/S0032-9592(03)00274-7 (2004).

42 Park, S.-C. et al. Amphipathic a-helical peptide, HP (2-20), and its analogues derived from Helicobacter pylori: pore formation mechanism in various lipid compositions. Biochimica et Biophysica Acta (BBA)-Biomembranes 1778, 229-241, doi:10.1016/j.bbamem.2007.09.020 (2008).

43 Hartmann, M. et al. Damage of the bacterial cell envelope by antimicrobial peptides gramicidin $\mathrm{S}$ and PGLa as revealed by transmission and scanning electron microscopy. Antimicrob Agents Chemother 54, 3132-3142 (2010).

44 Sultana, S. T., Babauta, J. T. \& Beyenal, H. Electrochemical biofilm control: a review. Biofouling 31, 745-758, doi:10.1080/08927014.2015.1105222 (2015).

45 Dröge, W. Free radicals in the physiological control of cell function. Physiol. Rev. 82, 47-95 (2002).

46 Albesa, I., Becerra, M. C., Battan, P. C. \& Paez, P. L. Oxidative stress involved in the antibacterial action of different antibiotics. Biochem. Biophys. Res. Commun. 317, 605-609, doi:10.1016/j.bbrc.2004.03.085 (2004).

47 Zhang, J., Neoh, K. G., Hu, X. \& Kang, E.-T. Mechanistic insights into response of Staphylococcus aureus to bioelectric effect on polypyrrole/chitosan film. Biomaterials 35, 7690-7698, doi:10.1016/j.biomaterials.2014.05.069 (2014).

48 Novogrodsky, A., Ravid, A., Rubin, A. L. \& Stenzel, K. H. Hydroxyl radical scavengers inhibit lymphocyte mitogenesis. Proc. Natl Acad. Sci. USA 79, 1171-1174 (1982).

$49 \mathrm{Kim}, \mathrm{Y}$. W. et al. Effect of electrical energy on the efficacy of biofilm treatment using the bioelectric effect. NPJ Biofilms Microbiomes 1, 15016, doi:10.1038/npjbiofilms.2015.16, http://www.nature.com/articles/npjbiofilms201516 \#supplementary-information (2015).

50 Jones, R. N. et al. Educational antimicrobial susceptibility testing as a critical component of microbiology laboratory proficiency programs: American Proficiency Institute results for 2007-2011. Diagn. Microbiol. Infect. Dis. 75, 357-360, doi:10.1016/j.diagmicrobio.2013.01.027 (2013).

51 Cañas-Duarte, S. J., Restrepo, S. \& Pedraza, J. M. Novel protocol for persister cells isolation. PLOS ONE 9, e88660, doi:10.1371/journal.pone.0088660 (2014).

52 Chen, C. Y., Nace, G. W. \& Irwin, P. L. A $6 \times 6$ drop plate method for simultaneous colony counting and MPN enumeration of Campylobacter jejuni, Listeria monocytogenes, and Escherichia coli. J. Microbiol. Methods 55, 475-479, doi:10.1016/ s0167-7012(03)00194-5 (2003).

$53 \mathrm{Cho}$, J. et al. The antifungal activity and membrane-disruptive action of dioscin extracted from Dioscorea nipponica. Biochimica et Biophysica Acta (BBA)Biomembranes 1828, 1153-1158, doi:10.1016/j.bbamem.2012.12.010 (2013).

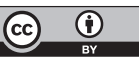

This work is licensed under a Creative Commons Attribution 4.0 International License. The images or other third party material in this article are included in the article's Creative Commons license, unless indicated otherwise in the credit line; if the material is not included under the Creative Commons license, users will need to obtain permission from the license holder to reproduce the material. To view a copy of this license, visit http://creativecommons.org/licenses/by/ $4.0 /$

(c) The Author(s) 2016

Supplementary Information accompanies the paper on the npj Biofilms and Microbiomes website (doi:10.1038/s41522-016-0003-0). 